\title{
Impact of training primary care physicians in behavioral counseling to reduce cardiovascular disease risk factors in Ecuador
}

\author{
Manuel E. Baldeón, ${ }^{1}$ Marco Fornasini, ${ }^{1}$ Nancy Flores, ${ }^{2}$ Philip A. Merriam, ${ }^{3}$ \\ Milagros Rosal, ${ }^{3}$ Juan C. Zevallos, ${ }^{4}$ and Ira Ocken ${ }^{3}$
}

Suggested citation

Baldeón ME, Fornasini M, Flores N, Merriam PA, Rosal M, Zevallos JC, et al. Impact of training primary care physicians in behavioral counseling to reduce cardiovascular disease risk factors in Ecuador. Rev Panam Salud Publica.2018;42:e139. https:/ /doi.org/10.26633/RPSP.2018;42:e139

ABSTRACT Objective. To assess the feasibility of implementing a physician-based, patient-centered counseling intervention model in Ecuador to improve the ability of primary care physicians (PCPS) to reduce cardiovascular disease (CVD) risk factors among patients.

Methods. This was a randomized clinical trial conducted in primary care clinics in Quito in 2014 - 2016. Participants included 15 PCPs and their adult patients at high risk of developing type-2 diabetes. A physician-based and patient-centered counseling program was delivered to eight PCPs. Seven PCPs who did not receive the training comprised the control group. The patient experience was assessed by a patient exit interview (PEI). Assessment of the patient's anthropometrics, blood pressure, and blood biochemistry parameters were conducted. Changes within and between groups were estimated utilizing chisquare, ANOVA, paired t-tests, and coefficient with intervention.

Results. A total of 197 patients participated, 113 in the intervention care group (ICG) and 84 in the usual care group (UCG); 99 patients $(87.6 \%)$ in the ICG and 63 (75\%) in the UCG completed the study. Counseling steps, measured by the PEI, were significantly higher in the ICG (8.9 \pm 1.6 versus $6.6 \pm 2.3 ; P=0.001)$. Comparison of the estimated difference between the ICG and the UCG showed greater decreases in HbA1c and total cholesterol in the ICG. Within the ICG, there were significant improvements in weight, BMI, HbA1C, total cholesterol, and LDL-cholesterol.

Conclusions. Training PCPS in a patient-centered behavioral intervention for CVD risk factor reduction is feasible and efficacious for reducing CVD risk factors in Ecuador. Developed and developing countries alike could benefit from such an intervention.

Keywords Cardiovascular diseases; health human resource training; diabetes mellitus, type 2; cholesterol, HDL; cholesterol, LDL; blood pressure; Ecuador.

\footnotetext{
Center for Biomedical Research, Eugenio Espejo College of Health Science, Universidad Tecnológica Equinoccial, Quito, Ecuador. Send correspondence to Manuel E. Baldeón, manuel.baldeon@ute.edu.ec
}

\footnotetext{
Center for Translational Research, Universidad de las Américas, Quito, Ecuador.

Department of Medicine, University of Massachusetts Medical School, Worcester, Massachusetts, United States of America.
}
Department of Medical and Population Health Sciences Research, Herbert Wertheim College of Medicine, Florida International University, Miami, Florida, United States.


Overweight and obesity are public health problems worldwide. Middleincome countries, such as Ecuador, are simultaneously experiencing the presence of both deficient and excess nutrition (1). It has been estimated that in developing countries, excess nutrition and diseases associated with it can have a greater negative impact on morbidity and mortality than in developed countries (2). In recent decades, the leading causes of death in Ecuador have included cardiovascular disease (CVD), type 2 diabetes, and hypertension (3).

In 2013, the Ministry of Public Health of Ecuador published the National Health and Nutrition Examination Survey. The results indicated that $62.8 \%$ of the adult population is overweight or obese (4) and that the prevalence of CVD risk factors is increasing. In addition, among adults over 50 years of age, approximately half are dyslipidemic, $22.7 \%$ have hypertension, $10.3 \%$ have diabetes, and $57.2 \%$ smoke cigarettes. Other metabolic conditions associated with CVD are also common in adults; prevalence rates of metabolic syndrome $(27.7 \%)$ are higher than those reported for the adult population of the United States (22.0\%) in 2010. The same survey also indicated that $45 \%$ of adults are sedentary and that medication adherence is poor $(48.9 \%$ reported not taking their medication). Moreover, type 2 diabetes, the primary cause of death in Ecuador, is a major risk factor for CVD (3).

According to the World Health Organization's Alma-Ata principles, primary care should be a cornerstone of patient health care (5). Therefore, it is necessary to implement intervention strategies that help primary care physicians (PCPs) and health care systems to decrease the prevalence of CVD risk factors in Ecuador. Intervention strategies to decrease CVD risk factors need to consider the local context, including the characteristics of national health care systems and the knowledge and attitudes of patients (6).

Previous work in the United States among Latino populations has demonstrated the effectiveness of an intervention model using physician-delivered, patient-centered counseling within a supportive office environment to decrease CVD risk factors (7). That study showed that brief patient-centered nutrition counseling delivered by physicians combined with office support can produce beneficial changes in patient diet, weight, and blood lipid concentrations.

Consequently, the objective of the present study was to assess the feasibility of implementing a physician-based, patient-centered counseling intervention model in Ecuador to improve the ability of PCPs to reduce CVD risk factors among their patients.

\section{MATERIALS AND METHODS}

\section{Clinical sites selection}

Clinical system networks in Quito were selected based on their willingness to participate; provision of care to large, middle- and low-income populations; and the availability of electronic medical records. Six health care systems that met these criteria were invited to participate; four accepted: two private, one public, and one private/public. For the intervention care group (ICG), one public and two private clinics from these health systems were randomly selected. In these, the PCPs were trained on patient-centered counseling methods and received office system prompts for delivering the intervention. For the usual care group (UCG), one private, one public, and one private/public clinic were randomly selected. In these, PCPs continued their usual practice. Primary care physicians and internists that were regularly working in the clinics were invited to participate. A total of 15 physicians participated, eight in the ICG and seven in the UCG.

\section{Training on nutrition, physical activity, and statin use}

Training of physicians in the ICG included an intensive 4-hour session comprising a didactic component on the relationship between behavior and CVD risk factors and a review of the guidelines for statin therapy. Physicians received a training binder with copies of the lecture slides, the counseling intervention algorithms, a sample counseling script, and other intervention materials (diet and exercise goal sheets, the Diet and Physical Activity Risk Assessment [DARA] guide, and the statin use algorithm, patient education materials, and a step counter). Subsequently, physicians were introduced to patient-centered counseling, its algorithms, and the statin use algorithm per the current guidelines for the United States $(8,9)$. Since there are no local guidelines for statin use, most physicians follow the United States or European guidelines. Physicians in the ICG were also taught to implement a 7 - 10-minute patient-centered counseling protocol that included information on the benefits of walking and other easy physical activities, as well as dietary counseling, particularly reducing the consumption of simple carbohydrates, saturated fat, and salt, and increasing consumption of fruits and vegetables.

To evaluate the physicians' changes in attitudes and knowledge on physical activity, diet, and lipid therapy, and any improvements in counseling skills, preand post-training assessments using a previously validated instrument were conducted among the ICG (7). Physicians were taught to use the office support materials with their patients through live examples followed by role-playing with fellow PCPs who alternating roles as clinician, patient, and observer. Further practical reinforcement training was carried out by a member of the research team in the physicians' offices.

During the 6 months of the study, physicians in the ICG delivered the interventions using a package affixed to each study patient's chart. The office support included a folder containing: the patient's most recent lipid levels with a prompt highlighting the direct low density lipoprotein cholesterol (LDL-C) value, a completed DARA questionnaire (for the initial visit only), DARA guide, dietary goal sheets to use with the patient, the counseling algorithm, and a copy of the national cholesterol management guidelines. Clinic personnel, along with the support of the research team, tracked patients due for visits.

\section{Pre-eligibility and patient selection}

Study participants were selected using the clinic's patient appointment database. A recruitment call list was generated as needed, screening for patient age and body mass index (BMI) criteria (age $\geq$ 30 years and $\mathrm{BMI} \geq 25$ ). Those identified received a pre-screening recruitment by telephone to verify age, BMI, and statins use. Patients taking lipid-lowering medications, those with known coronary heart disease, and those with secondary causes of hyperlipidemia were excluded.

Members of the research team made the pre-eligibility screening telephone calls. 
When a pre-eligible patient showed interest in participating, a fasting screening appointment was scheduled. Participants that accepted screening received a study identification code and were registered in the tracking database.

\section{Screening assessment}

The day before the screening appointment, participants were reminded of the visit and the required overnight fasting. At the appointment, research staff verified the patient's eligibility and obtained their informed consent. A venous blood sample was taken to measure: glucose and a complete lipid profile (total cholesterol [Total-C]; direct LDL-C, high density lipoprotein cholesterol [HDL-C]; and triglycerides). Height and weight were measured with light clothing and no shoes. Blood pressure was measured after 10 minutes of rest. The clinic coordinator then calculated the risk of developing type 2 diabetes using the Stern formula (10), notifying each patient of their eligibility and sharing the laboratory results with their physician.

Eligible patients were scheduled to return for a baseline physician visit. Prior to the baseline visit, the coordinator asked the clinical laboratory to complete the determinations of glycated hemoglobin $(\mathrm{HbA} 1 \mathrm{c}), \mathrm{AST}$, and ALT, and to store serum samples for insulin determinations. All insulin samples were assayed in a single batch at the end of the study.

\section{Baseline visit with a physician}

Twenty-four hours before the baseline appointment, patients were reminded of the visit. Before the physician's consultation, each participant provided a definitive informed consent. The clinic coordinator administered the DARA questionnaire, which was used for the physician's counseling with each patient. Patients also completed a baseline survey that included sociodemographic information, diet and physical activity, family history of chronic diseases, and use of alcohol. Within the diet section, there were 10 questions regarding consumption of fruits and vegetables, and 17 questions related to fat consumption. To quantify fat and fruits/vegetables consumption, a score was applied based on previous studies (7). Finally, the research staff administered a depression screening to each participant using the Center for Epidemiologic Studies Depression Scale $(11,12)$. A score $\geq 16$ was reported to the patient's physician since it indicates being at high risk for depression.

Appointments with the physician lasted approximately 20 minutes. After this baseline visit, patients were met by a research staff member who administered the "Patient Exit Interview" (PEI) to evaluate how well the physician had followed the 12 patient-centered counseling steps (7).

\section{6-month assessment visit}

The clinic coordinator scheduled a 30-minute appointment 6 months after the baseline clinical visit and reminded each patient to fast overnight before the visit. The day of the appointment, the clinic coordinator administered the same assessment instruments as in the baseline visit, except for the DARA. The patient's weight and blood pressure were measured. A question regarding medication compliance was included in the final survey; it asked for the number of days per week that the patient complied with prescribed medication. A blood sample was also obtained to determine the same biochemical parameters measured at baseline. Patients received a US\$ 6 incentive after each study visit.

\section{Anthropometric measurements}

Anthropometric measurements were taken at the baseline visit and at the 6-month follow-up visit. Weight and height were recorded by trained staff using standardized techniques and calibrated equipment (13). For weight measurement, an electronic SECA ${ }^{\circledR} 213$ scale (Seca GmbH \& Co., Hamburg, Germany); for height measurement, a vertically-mounted SECA ${ }^{\circledR} 213$ stadiometer was used. Height was measured to the nearest $1.0 \mathrm{~cm}$.

\section{Blood samples}

Qualified staff obtained venous blood samples from patients in the morning (after overnight fasting). Samples (plasma and serum) were centrifuged within 2 hours and processed immediately, except for insulin, which was measured in all samples at the end of the study period. Each patient was assigned a unique bar-code identification to accurately trace samples (4).

\section{Glucose, lipid profile, glycated hemoglobin, and insulin measurements}

Blood glucose, total-C, direct LDL-C, HDL-C, and triglycerides were determined on a COBAS 6000-E601 (Hitachi High-Technologies Corporation / Minati-ku, Tokyo, Japan) using standard reagents (Roche Diagnostics $\mathrm{GmbH}$, Mannheim, Germany). Serum insulin was determined using an electro-chemiluminescence immunoassay following the manufacturer's instructions (Roche Diagnostics GmbH, Mannheim, Germany) and chemiluminescent emission was measured using a fully automated analyzer system, the COBAS 6000 E601. Glycated hemoglobin was determined by immunoturbimetry/Acs anti-HbA1c, using the COBAS 6000 E601 according to the manufacturer's instructions. Blood biochemistry analyses were conducted at NetLab (Quito, Ecuador), a laboratory certified by the College of American Pathologists and the Brazilian Society of Clinical Pathologists (14).

To calculate the homeostasis model assessment-estimated insulin resistance (HOMA), the study utilized a modified formula by Wallace and colleaguesfasting plasma glucose $(\mathrm{mg} / \mathrm{dL})$ multiplied by fasting serum insulin $(\mathrm{mU} / \mathrm{ml})$, divided by 405 (14).

\section{Ethics}

The Institutional Review Boards of the University of Massachusetts Medical School (Worcester, Massachusetts, United States) and Universidad de Las Américas (Quito, Ecuador) approved the study each year. The study followed the ethical standards of the Declaration of Helsinki (15).

\section{Statistical analyses}

Sample size was estimated by considering PEI scores with a standard deviation (SD) obtained by the authors from previous studies among a Latino population in Massachusetts, United States. A PEI score difference of 2 points \pm 2.9 was used. Considering this study's design and an estimated intra-cluster correlation value for PEI of 0.3 per the Worcester Area Trial for Counseling in Hyperlipidemia (WATCH) study (7), a sample of 200 subjects provided $84 \%$ power; thus, patients were assigned to each of the two study groups at a ratio of 1:1. 
Descriptive statistics were calculated for continuous variables; frequencies and percentages were calculated for categorical variables. Analyses were performed with intention to treat. Differences between groups were assessed with chisquare test and ANOVA. Differences within groups were assessed with paired $\mathrm{t}$-test or the corresponding non-parametric statistics. Coefficient with intervention, which is the estimated difference between the ICG and the UCG according to the change in the measured biochemical parameter, was calculated. Adjusted analyses were carried out that accounted for the patient clustering within physicians at the individual sites (to account for correlations of patients treated by individual physicians).

Mean differences between the ICG and the UCG for PEI score, anthropometric and blood pressure measures, and blood biochemistry parameters were estimated and tested using mixed effects linear regression models with physician as a random effect. This is a method suggested by Donner and Klar (16). Statistical analyses were performed with SAS ${ }^{\circledR}$ v9.4 software (Armonk, New York, United States). Descriptive statistics are presented as means and SD, and $P<0.05$ was considered to be statistically significant.

\section{RESULTS}

Data were analyzed by simple, unadjusted comparisons, as well as by considering the clustered study design. Since the outcome of both types of analyses were similar and the conclusions were the same, only the results of the unadjusted analysis are presented here.

The study period lasted from October 2014 - July 2016, with the 6-month follow-up visits being held from April 2015 - July 2016. Initially, 1397 patients that met eligibility criteria (age and BMI) were approached through a telephone call (Figure 1). Of these, 1172 were excluded because they declined to participate, did not come to the appointment, were not accessible, or did not meet the definitive eligibility criteria. The 225 patients who were eligible according to the Stern formula were allocated to the ICG $(n=125)$ and the UCG $(n=100)$. However, only 113 patients in the ICG and 84 in the UCG attended the baseline physician appointment. Of these, 99 patients in the ICG and 63 in the UCG completed the study (Figure 1).

FIGURE 1. Flowchart of data analyzed to evaluate the impact that behavioral counseling training of primary care physicians has on reducing cardiovascular risk factors in Ecuador

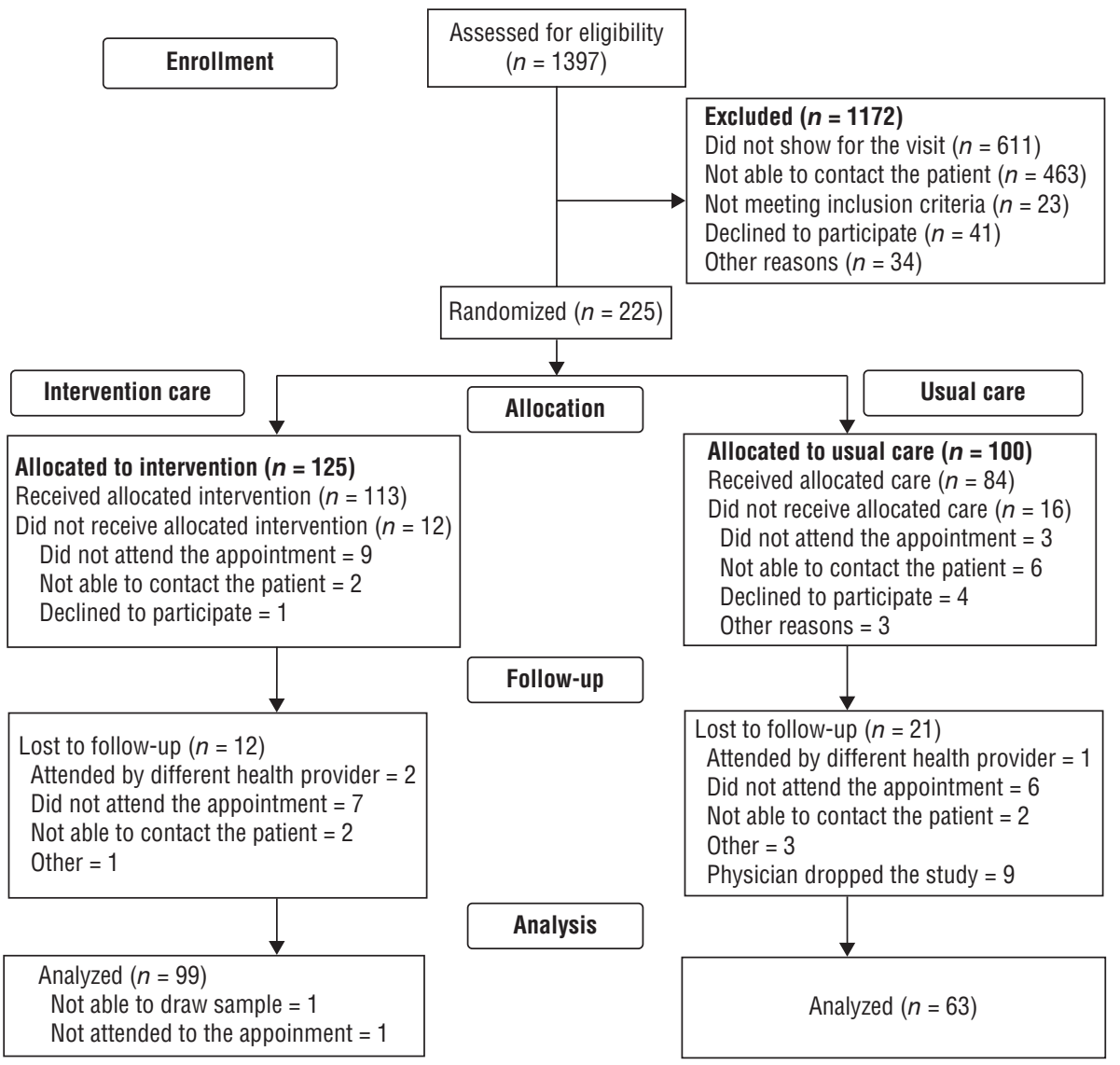

Source: Prepared by the authors from the study results.

\section{Patient characteristics at baseline}

A total of 197 patients were included in the study, $138(70 \%)$ women and $59(30 \%)$ men. At baseline, ICG and UCG were similar in age, gender, marital status, employment, family income, and the proportion of first-degree relatives with type 2 diabetes. However, educational level was higher in the ICG (UCG 6 \pm 3.1 versus ICG 7.4 \pm 3.7 ; $P=0.006)$. Also, at baseline both treatment groups were similar in clinical and blood biochemical variables, except for $\mathrm{HbA1c}$ which was higher in the ICG (Table 1).

\section{Physicians' attitudes before and after training}

After counseling training, PCPs scored significantly better in their attitudes toward providing advice on physical activity, diet, and lipid therapy (from $14.5 \pm 4.1$ to $11.0 \pm 2.1$ in a reverse scale; $P<0.05)$.

\section{Feasibility of a patient-centered counseling program}

To evaluate patient perception of PCPs regarding the behavioral counseling intervention, a PEI was done after the baseline visit. As expected, physicians in the ICG delivered a significantly higher number of counseling steps than those in the UCG, $8.5 \pm 2.0$ versus $6.1 \pm 2.6$, respectively. Counseling steps regarding diet, physical activity, and the prescription of lipid-lowering medication were addressed significantly more often within the ICG than the UCG (Table 2).

\section{Changes in diet, physical activity, and depression}

Changes in healthy dietary behaviors were recorded using the Block Dietary 
Fat Screener and Block Fruit/Vegetable screeners (15); physical activity was recorded using the Women's Health
Initiative Physical Activity Questions $(17,18)$. Patients in the ICG reduced the amount of fat intake from baseline to the
TABLE 1. Baseline anthropometric and biological parameters of treatment groups in a study of the impact that behavioral counseling training of primary care physicians has on reducing cardiovascular risk factors in Ecuador

\begin{tabular}{|c|c|c|c|}
\hline Demographic characteristics $^{\mathrm{a}}$ & Usual care group & Intervention group & $P$ value \\
\hline $\mathrm{BMI}\left(\mathrm{kg} / \mathrm{m}^{2}\right)$ & $\begin{array}{c}31.8 \pm 4.8 \\
(n=83)\end{array}$ & $\begin{array}{l}32.2 \pm 4.9 \\
(n=113)\end{array}$ & 0.596 \\
\hline Weight (kg) & $\begin{array}{c}79.8 \pm 14.2 \\
(n=83)\end{array}$ & $\begin{array}{c}79.0 \pm 14.8 \\
(n=113)\end{array}$ & 0.710 \\
\hline $\mathrm{SBP}(\mathrm{mmHg})$ & $\begin{array}{c}122.2 \pm 13.5 \\
(n=83)\end{array}$ & $\begin{array}{c}122.6 \pm 15.5 \\
(n=112)\end{array}$ & 0.850 \\
\hline $\mathrm{DBP}(\mathrm{mmHg})$ & $\begin{array}{c}79.4 \pm 11.2 \\
(n=83)\end{array}$ & $\begin{array}{c}79.8 \pm 13.1 \\
(n=112)\end{array}$ & 0.826 \\
\hline Glucose (mg/dL) & $\begin{array}{c}104.1 \pm 22.9 \\
(n=84)\end{array}$ & $\begin{array}{c}101.5 \pm 28.2 \\
(n=113)\end{array}$ & 0.495 \\
\hline $\mathrm{HbA1C}(\%)$ & $\begin{array}{l}6.0 \pm 1.1 \\
(n=80)\end{array}$ & $\begin{array}{c}6.4 \pm 1.3 \\
(105)\end{array}$ & 0.023 \\
\hline $\mathrm{TC}(\mathrm{mg} / \mathrm{dL})$ & $\begin{array}{c}206.6 \pm 34.0 \\
(n=84)\end{array}$ & $\begin{array}{c}209.7 \pm 37.8 \\
(n=113)\end{array}$ & 0.553 \\
\hline $\mathrm{LDL}(\mathrm{mg} / \mathrm{dL})$ & $\begin{array}{c}129.4 \pm 29.6 \\
(n=82)\end{array}$ & $\begin{array}{c}129.0 \pm 30.6 \\
(n=105)\end{array}$ & 0.921 \\
\hline $\mathrm{HDL}(\mathrm{mg} / \mathrm{dL})$ & $\begin{array}{c}43.0 \pm 10.6 \\
(n=84)\end{array}$ & $\begin{array}{c}42.9 \pm 10.5 \\
(n=113)\end{array}$ & 0.968 \\
\hline $\mathrm{TG}(\mathrm{mg} / \mathrm{dL})$ & $\begin{array}{c}178.9 \pm 94.8 \\
(n=84)\end{array}$ & $\begin{array}{c}200.3 \pm 129.3 \\
(n=112)\end{array}$ & 0.201 \\
\hline Insulin & $\begin{array}{c}21.1 \pm 23.3 \\
(n=45)\end{array}$ & $\begin{array}{c}18.6 \pm 10.1 \\
(n=83)\end{array}$ & 0.394 \\
\hline HOMA & $\begin{array}{l}5.7 \pm 8.8 \\
(n=45)\end{array}$ & $\begin{array}{l}4.5 \pm 2.5 \\
(n=83)\end{array}$ & 0.246 \\
\hline
\end{tabular}

a $\mathrm{BMI}=$ body mass index; $\mathrm{SBP}=$ systolic blood pressure; $\mathrm{DBP}=$ diastolic blood pressure; HbA1C = glycosylated hemoglobin; TC = total cholesterol; LDL = low-density lipoprotein-cholesterol; HDL = high-density lipoprotein-cholesterol; $\mathrm{TG}=$ triglycerides $; \mathrm{HOMA}=$ Homeostasis Model Assessment.

Source: Prepared by the authors from the study results. end of the study, from a score of $17.2 \pm 7$ to $14.3 \pm 7(P=0.005)$, while patients in the UCG did not significantly change their fat intake $(P=0.756)$. There were no significant differences in the consumption of fruits and vegetables, either between or within treatment groups. Regarding physical activity, both treatment groups presented a low-moderate physical activity, and this was comparable throughout the study period. In addition, at baseline the prevalence of patients at high risk for depression was higher in the ICG than in the UCG $(56.3 \%$ versus $32.9 \%$; $P=0.001$ ); however, this difference decreased by the end of the study and was not statistically significant (45.1\% versus $33.9 \%$ ).

\section{Changes in anthropometric parameters and blood pressure}

Comparison between treatment groups showed that there were no significant differences in BMI and weight, at either baseline or at the end of the study period. However, as shown in Table 3, there was a statistically significant decrease in BMI and weight in both treatment groups from baseline through the end of the study period. The mean change was greater in the ICG.

Blood pressures, both systolic and diastolic, were comparable between groups at baseline and at the end of the study

TABLE 2. Mean score of behavior counseling steps discussed by the primary care physician (PCP) according to the patient exit interview (PEI), by treatment group, in a study of PCP training to reduce cardiovascular risk factors in Ecuador

\begin{tabular}{|c|c|c|c|c|}
\hline \multirow{2}{*}{ Steps discussed or taken by the PCP } & \multirow{2}{*}{ Overall (\%) } & \multirow{2}{*}{$\begin{array}{c}\text { Intervention care group } \\
(\%) \\
\end{array}$} & \multirow{2}{*}{$\begin{array}{c}\text { Usual care group } \\
(\%)\end{array}$} & \multirow{2}{*}{$P$ value } \\
\hline & & & & \\
\hline 1. Cholesterol & $175 / 192(91.1)$ & $103 / 111(92.8)$ & $72 / 81(88.9)$ & 0.442 \\
\hline 2. Diet-cholesterol connection & $183 / 193(94.8)$ & $109 / 112(97.3)$ & $74 / 81(91.4)$ & 0.098 \\
\hline 3. Recommended dietary change to lower cholesterol & $176 / 192(91.7)$ & $107 / 111(96.4)$ & $69 / 81(85.2)$ & 0.007 \\
\hline 4. Past efforts to lower cholesterol & $100 / 189(52.9)$ & $76 / 111(68.5)$ & $24 / 78(30.8)$ & 0.000 \\
\hline 5. Problems making dietary changes & $92 / 187(49.2)$ & $62 / 109(56.9)$ & $30 / 78(38.5)$ & 0.017 \\
\hline 6. Solutions to the problems & $94 / 102(92.2)$ & $61 / 64(95.3)$ & $33 / 38(86.8)$ & 0.145 \\
\hline 7. Made an agreement with patient on specific dietary changes or goals & $169 / 190(88.9)$ & $103 / 110(93.6)$ & $66 / 80(82.5)$ & 0.019 \\
\hline 8. Provided or sent nutrition materials to patient & $126 / 192(65.6)$ & $109 / 112(97.3)$ & $17 / 80(21.3)$ & 0.000 \\
\hline 9. Referred patient for nutrition counseling & 22/192 (11.5) & $11 / 111(9.9)$ & $11 / 81(13.6)$ & 0.494 \\
\hline 10. Planned future visit to address cholesterol & 127/193 (65.8) & $81 / 112(72.3)$ & $46 / 81(56.8)$ & 0.031 \\
\hline 11. Prescribed medication to lower cholesterol & $34 / 193(17.6)$ & $28 / 112(25.0)$ & $6 / 81(7.4)$ & 0.000 \\
\hline 12. Discussed beginning or continuing exercise & $171 / 190(90.0)$ & $108 / 110(98.2)$ & $63 / 80(78.8)$ & 0.000 \\
\hline Group & \multicolumn{2}{|c|}{ No. of patients } & \multicolumn{2}{|c|}{ Mean PEI score \pm SD } \\
\hline Intervention care & \multicolumn{2}{|c|}{113} & \multicolumn{2}{|c|}{$8.5 \pm 2.0$} \\
\hline Usual care & \multicolumn{2}{|c|}{84} & \multicolumn{2}{|c|}{$6.1 \pm 2.6$} \\
\hline Total & \multicolumn{2}{|c|}{197} & \multicolumn{2}{|c|}{$7.5 \pm 2.5$} \\
\hline
\end{tabular}

a $P<0.0001$ (ANOVA).

Source: Prepared by the authors from the study results. 
period. However, in the UCG there was a significant decrease in systolic blood pressure from baseline until the end of the study (Table 3).

\section{Changes in blood biochemical parameters}

As indicated above, baseline comparison between treatment groups showed that serum concentrations of $\mathrm{HbA} 1 \mathrm{c}$ were significantly lower in the UCG. After 6 months of intervention, the CWI was estimated; this CWI is the estimated difference between ICG versus UCG according to the change in the measured biochemical parameter. There were no statistical differences in CWI for serum glucose, direct LDL-C, HDL-C, triglycerides, and insulin between the groups. However, there were statistically greater decreases for $\mathrm{HbA} 1 \mathrm{c}$ and Total- $\mathrm{C}$ in the ICG than in the UCG.

Assessment of changes within groups showed that in the UCG, only serum concentrations of direct LDL-C significantly decreased from baseline to the end of the study period ( $-7 \mathrm{mg} / \mathrm{dL})$. However, in the ICG there were significant decreases in serum concentrations of $\mathrm{HbA1c}$, Total- $\mathrm{C}$, and direct LDL-C (Table 4). Patients in the ICG were significantly more likely to receive lipid-lowering medications than the
UCG, $25.0 \%$ versus $7.4 \%$ respectively $(P=0.001)$. In the ICG, 19 patients received statins and 6 received fibrates; whereas in the UCG, none received statins, 5 received fibrates, and 1 received an inhibitor of protein convertase subtilisin/kexin type 9. Further analysis considering only the individuals that did not receive statin treatment showed that patients in the ICG improved their serum LDL concentrations from $125.8 \pm 26.1$ to $122.0 \pm 33.0(P=0.001)$. However, patients who did not receive statins in the UCG decreased their serum LDL concentrations, from $127.7 \pm 30.7$ to $121.0 \pm 30.4$; however, this decrease was not statistically significant, $(P=0.057)$.

TABLE 3. Changes in anthropometric parameters and blood pressure, by treatment group, at baseline and 24 weeks after the intervention to reduce cardiovascular risk factors through behavioral counseling in Ecuador

\begin{tabular}{|c|c|c|c|c|c|c|c|c|}
\hline \multirow{2}{*}{ Parameters $^{\mathrm{a}}$} & \multicolumn{4}{|c|}{ Usual care group } & \multicolumn{4}{|c|}{ Intervention care group } \\
\hline & Baseline & Final & Mean change & $P$ value & Baseline & Final & Mean change & $P$ value \\
\hline $\mathrm{BMI}$ & $\begin{array}{c}31.9 \pm 4.8 \\
n=54\end{array}$ & $\begin{array}{c}31.6 \pm 4.9 \\
n=54\end{array}$ & -0.36 & 0.035 & $\begin{array}{c}32.5 \pm 5.1 \\
n=96\end{array}$ & $\begin{array}{c}31.7 \pm 4.9 \\
n=96\end{array}$ & -0.77 & $0.002^{b}$ \\
\hline SBP & $\begin{array}{c}122.7 \pm 13.8 \\
n=58\end{array}$ & $\begin{array}{c}118 \pm 9.7 \\
n=58\end{array}$ & -4.64 & $0.024^{b}$ & $\begin{array}{c}122.3 \pm 14.4 \\
n=97\end{array}$ & $\begin{array}{c}120 \pm 16.9 \\
n=97\end{array}$ & -2.26 & 0.215 \\
\hline
\end{tabular}

${ }^{\mathrm{a}} \mathrm{BMI}=$ body mass index; $\mathrm{SBP}=$ systolic blood pressure; $\mathrm{DBP}=$ diastolic blood pressure.

b Statistically significant.

Source: Prepared by the authors from the study results.

TABLE 4. Comparison in blood biochemistry parameters, within treatment groups, at baseline and 24 weeks after the intervention to reduce cardiovascular risk factors through behavioral counseling in Ecuador

\begin{tabular}{|c|c|c|c|c|c|c|c|c|}
\hline \multirow{2}{*}{ Parameters $^{\mathrm{a}}$} & \multicolumn{2}{|c|}{ Usual care group } & \multirow{2}{*}{ Mean change } & \multirow{2}{*}{$P$ value } & \multicolumn{2}{|c|}{ Intervention care group } & \multirow{2}{*}{ Mean change } & \multirow{2}{*}{$P$ value } \\
\hline & Baseline & Final & & & Baseline & Final & & \\
\hline Glucose & $\begin{array}{c}100.3 \pm 12.7 \\
n=63\end{array}$ & $\begin{array}{c}97 \pm 16.8 \\
n=63\end{array}$ & -3.27 & 0.087 & $\begin{array}{c}101.7 \pm 30.9 \\
n=92\end{array}$ & $\begin{array}{c}101.5 \pm 13.4 \\
n=92\end{array}$ & -0.16 & 0.951 \\
\hline TC & $\begin{array}{c}203.4 \pm 34.4 \\
n=63\end{array}$ & $\begin{array}{c}198.1 \pm 33.5 \\
n=63\end{array}$ & -5.29 & 0.129 & $\begin{array}{c}210.1 \pm 38.1 \\
n=92\end{array}$ & $\begin{array}{c}194.6 \pm 41.5 \\
n=92\end{array}$ & -15.47 & 0.000 \\
\hline HDL & $\begin{array}{c}42.6 \pm 10.5 \\
n=63\end{array}$ & $\begin{array}{c}43.7 \pm 12.6 \\
n=63\end{array}$ & $+1,06$ & 0.347 & $\begin{array}{c}43.1 \pm 10.3 \\
n=91\end{array}$ & $\begin{array}{c}42 \pm 11.2 \\
n=91\end{array}$ & -1.11 & 0.165 \\
\hline TG & $\begin{array}{c}171.3 \pm 95.5 \\
n=63\end{array}$ & $\begin{array}{c}180.3 \pm 106.5 \\
n=63\end{array}$ & +8.97 & 0.326 & $\begin{array}{c}193.8 \pm 111.4 \\
n=91\end{array}$ & $\begin{array}{c}181.1 \pm 105.4 \\
n=91\end{array}$ & -12.65 & 0.136 \\
\hline Insulin & $\begin{array}{c}19.8 \pm 20.4 \\
n=61\end{array}$ & $\begin{array}{c}25.9 \pm 29.4 \\
n=59\end{array}$ & +6.1 & 0.667 & $\begin{array}{c}18.7 \pm 9.9 \\
n=95\end{array}$ & $\begin{array}{c}20.6 \pm 20.4 \\
n=71\end{array}$ & +1.9 & 0.228 \\
\hline
\end{tabular}

${ }^{a} \mathrm{HbA1C}=$ glycosylated hemoglobin; $\mathrm{TC}=$ total cholesterol; $\mathrm{LDL}=$ low-density lipoprotein-cholesterol; $\mathrm{HDL}=$ high-density lipoprotein-cholesterol; $\mathrm{TG}=$ triglycerides; $\mathrm{HOMA}=\mathrm{Homeostasis}$ Model Assessment. 


\section{Comparison of medication compliance}

Self-reported patient medication compliance was also evaluated. Results showed that $98.3 \%$ of patients in the ICG took medication as prescribed $5-7$ days per week, while only $86.7 \%$ of patients in the UCG did so in the same period of time $(P=0.042)$.

\section{DISCUSSION}

This study demonstrated that it is possible to implement an effective program to decrease CVD risk factors in private and public primary care clinics in Quito through an intervention of physician-based, patient-centered counseling with office support. Most participating PCPs had a favorable attitude towards the study. PCPs from the ICG more frequently performed the counseling steps and followed the guidelines to decrease CVD risk factors in their patients. In addition, we observed that patients in the ICG significantly decreased their fat consumption and risk of depression, and improved their weight, BMI, $\mathrm{HbA} 1 \mathrm{c}$, Total-C, and direct LDL-C.

Previous work has shown that lipid management programs facilitated during physician visits result in a decrease in CVD risk factors. Our previous work, WATCH (7), in Massachusetts, evaluated the efficacy of an intervention of physician-delivered patient-centered counseling with office support, showing significant beneficial changes in patient diet, weight, and blood lipid levels after 1 year. In that study, patients attended by physicians who had received the behavioral counseling training had lower saturated fat intake (10.3\% decrease), a reduction in body weight $(2.3 \mathrm{~kg})$, and a decrease in LDL-C $(3.8 \mathrm{mg} / \mathrm{dL})$. In the present study, physician training plus office support also resulted in reduced fat intake and weight, similar to that seen in the WATCH study; and the decrease in body weight (ICG -1.8 versus UCG $-0.91 \mathrm{~kg} / \mathrm{m}^{2}$ ) also resulted in a significant BMI decrease, greater than that observed by WATCH.

In addition, in the current study, patients in the ICG had lower blood $\mathrm{HbA1c}$, Total-C, and direct LDL-C by the end of the intervention. A significant reduction of direct LDL-C was observed in the ICG regardless of statin use, although the reduction seen in those on statins was greater. It is noticeable that none of the subjects in the UCG received statins, although all subjects were overweight or obese and were at risk of developing diabetes. A study that assessed the use of effective therapies in individuals with a history of coronary heart disease or stroke in South America showed that an important proportion did not receive any proven therapy (19). In the present study, we saw a similar phenomenon in the UCG where statin therapy was not used. Potential barriers to treatment access in settings similar to Ecuador include the high cost and lack of medicines, and limited access to health care and specialists; other variables affecting treatment adherence and health care attendance are good communication and trust between patients and physicians (6). Interventions to improve physicians' capacity to counsel patients could contribute to closing the gaps in the use of proven medications and improving health care provision.

Together, these results indicate that implementation of an intervention of physician-delivered, patient-centered counseling with office support is feasible in Ecuador, and that methodologies originally developed for a United States population are equally applicable to a country on a different point of the socioeconomic continuum.

The current project was primarily a feasibility study, and is in many ways different from the larger WATCH study (7). Fifteen physicians and 197 patients from 4 different clinical systems participated in the present study, while 45 PCPs and 1162 patients from 12 separate patient care units were part of the WATCH trial. In the WATCH study, identification of an at-risk population was determined by abnormal lipid profiles, while in the current report individuals with increased risk to develop diabetes using the Stern estimation was used as the inclusion criterion. The indicated eligibility criteria for both studies could have resulted in a different profile of patients regarding CVD risk factors. The intervention lasted 6 months in the present study and 1 year in the WATCH study. However, physician training and the components of the patient-centered counseling model with office support were similar for the two studies. These two studies show that physician training and the tools used are effective for decreasing CVD risk factors in at-risk populations. These results encourage the implementation of larger studies with similar intervention methodologies in developing countries where cardiovascular diseases are major public health problems.

Limitations. As indicated, this feasibility study was carried out with a limited number of PCPs and clinics that could have specific administrative and health care provision characteristics, which could limit the generalizability of current results. Also, a follow up of 6 months could be an insufficient time to generate recommendations for the implementation of this educational intervention.

\section{Conclusions}

Training PCPs in a patient-centered behavioral intervention for CVD risk factor reduction is feasible and efficacious. The present intervention aligns with Alma-Ata principles that highlight the important role of a comprehensive primary care strategy to improve public health care. Implementation of this educational strategy could be an important public health measure to reduce cardiovascular disease.

Acknowledgements. The authors would like to thank Diana Flores, Liliana Valente, and Liz Ortiz for their dedication and contributions to the study.

Funding. This research project was made possible by the International Artherosclerosis Society (Houston, Texas, United States) and Pfizer Inc. (New York, New York, United States) under their Independent Grants for Learning \& Change Program (Grant Number 1153883). The funders had no role in the study design, data collection or analysis, decision to publish, or preparation of the manuscript.

\section{Conflict of interests: None declared.}

Disclaimer. Authors hold sole responsibility for the views expressed in the manuscript, which may not necessarily reflect the opinion or policy of the RPSP/ PAJPH and/or PAHO. 


\section{REFERENCES}

1. Freire WB, Silva-Jaramillo KM, RamírezLuzuriaga MJ, Belmont P, Waters WF. The double burden of undernutrition and excess body weight in Ecuador. Am J Clin Nutr. 2014;100(6):1636S-43S.

2. United Nations Food and Agriculture Organization. The double burden of malnutrition. Case studies from six developing countries. Rome: FAO; 2006. Available from: www.fao.org/docrep/pdf/ 009/a0442e/a0442e00.pdf Accessed 9 August 2018.

3. Ministerio de Salud Pública del Ecuador. Datos esenciales de salud: Una mirada a la década 2000 2010. Quito: MSP; 2010.

4. Freire W, Ramírez-Luzuriaga M, Belmont P, Mendieta M, Silva-Jaramillo K, Romero $\mathrm{N}$, et al. Encuesta Nacional de Salud y Nutrición, 2012. Vol 1. Quito: Ensanut-Ecu; 2014.

5. World Health Organization. Declaration of Alma-Ata. Proceedings of the International Conference on Primary Health Care. AlmaAlta; WHO; 1978. Available from: http:// www.who.int/publications/almaata_declaration_en.pdf?ua=1 Accessed 9 August 2018.

6. Legido-Quigley H, Camacho Lopez PA, Balabanova D, Perel P, Lopez-Jaramillo P, Nieuwlaat R, et al. Patients' knowledge, attitudes, behaviour and health care experiences on the prevention, detection, management and control of hypertension in Colombia: a qualitative study. PLoS One. 2015;10(4):e0122112.

7. Hebert JR, Ebbeling CB, Ockene IS, Ma Y, Rider L, Merriam PA, et al. A dietitiandelivered group nutrition program leads to reductions in dietary fat, serum cholesterol, and body weight: the Worcester Area Trial for Counseling in
Hyperlipidemia (WATCH). J Am Diet Assoc. 1999;99(5):544-52.

8. Goff DC, Lloyd-Jones DM, Bennett G, Coady S, D'Agostino RB, Gibbons R, et al. 2013 ACC / AHA guidelines on the assessment of cardiovascular risk. J Am Coll Cardiol. 2014;63(25):2935-59.

9. Stone NJ, Robinson JG, Lichtenstein $\mathrm{AH}$, Bairey Merz CN, Blum CB, Eckel RH, et al. 2013 ACC/AHA guideline on the treatment of blood cholesterol to reduce atherosclerotic cardiovascular risk in adults: a report of the American College of Cardiology/ American Heart Association Task Force on Practice Guidelines. Circulation. 2014;129 (25 Suppl 2):S1-45.

10. Stern MP, Williams $K$, Haffner SM. Identification of persons at high risk for type 2 diabetes mellitus: do we need the oral glucose tolerance test? Ann Intern Med. 2002;136(8):575-81.

11. Devins GM, Orme CM, Costello CG, Binik YM, Frizzell B, Stam HJ, et al. Measuring depressive symptoms in illness populations: psychometric properties of the Center for Epidemiologic Studies Depression (CES-D) Scale. Psychol Health. 1988;2(2):139-56.

12. Radloff L. The CES-D Scale: a self-report depression scale for research in the general population. Appl Psychol Meas. 1977;1(3):385-401.

13. Baldeón ME, Castro J, Villacrés E, Narváez L, Fornasini M. Hypoglycemic effect of cooked Lupinus mutabilis and its purified alkaloids in subjects with type-2 diabetes. Nutr Hosp. 2012;27(4):1261-6. Available from: http:// www.ncbi.nlm.nih.gov/pubmed/23165571. Accessed 4 September 2017.

14. Fornasini M, Castro J, Villacrés E, Narváez L, Villamar MP, Baldeón ME. Hypoglycemic effect of Lupinus mutabilis in healthy volunteers and subjects with dysglycemia. Nutr Hosp. 2012;27(2):425-33. Available from: http: / / www.ncbi.nlm.nih.gov/ pubmed/22732964 Accessed 4 September 2017.

15. World Medical Association. WMA Declaration of Helsinki: ethical principles for medical research involving human subjects. 2013. Available from: https://www. wma.net/policies-post/wma-declarationof-helsinki-ethical-principles-for-medicalresearch-involving-human-subjects / Accessed 9 August 2018.

16. Donner, Allan. Klar N. Design and analysis of cluster randomization trials in health research. New York City: Oxford University Press; 2000.

17. Nutrition Quest. Block dietary fat screener and block fruit/vegetable screener. Available from: https://nutritionquest. com/assessment/list-of-questionnairesand-screeners/ Accessed 5 August 2018.

18. National Cancer Institute. Epidemiology and Genomics Research Program: Women's health initiative physical activity questions. Available from: https://epi.grants.cancer. gov/paq/q103.html Accessed 5 August 2018.

19. Avezum A, Oliveira GBF, Lanas F, LopezJaramillo P, Diaz R, Miranda JJ, et al. Secondary CV prevention in South America in a community setting. Glob Heart. 2017;12(4):305-13.

Manuscript received on 30 October 2017. Accepted for publication on 12 July 2018. 
Objetivo. Evaluar la factibilidad de implementar un modelo de intervención en el médico y centrado en el paciente en Ecuador a fin de mejorar la capacidad de los médi-

Repercusión de la capacitación de médicos de atención primaria en orientación sobre el comportamiento para reducir los factores de riesgo de sufrir enfermedades cardiovasculares en Ecuador

\author{
Palabras clave
} cos de atención primaria (MAP) para reducir los factores de riesgo de enfermedades cardiovasculares (ECV) en los pacientes.

Métodos. Se llevó a cabo un ensayo clínico aleatorio en consultorios de atención primaria en Quito entre el 2014 y el 2016. Participaron 15 MAP y sus pacientes adultos con riesgo alto de padecer diabetes de tipo 2. Se proporcionó un programa médico orientativo centrado en el paciente a ocho MAP. Los siete que no recibieron la capacitación fueron el grupo testigo. Se evaluó la experiencia de los pacientes por medio de una encuesta de salida a los pacientes. Se evaluaron las medidas antropométricas, la presión arterial y los parámetros bioquímicos sanguíneos del paciente. Se calcularon los cambios entre los grupos y dentro de ellos por medio de pruebas de ji cuadrado, análisis de la varianza, pruebas $t$ pareadas y coeficiente con intervención.

Resultados. En total participaron 197 pacientes, 113 en el grupo de atención con intervención (GAI) y 84 en el grupo de atención habitual (GAH); 99 pacientes $(87,6 \%$ ) en el GAI y 63 (75 \%) en el GAH completaron el estudio entre el 2014 y el 2016. Los pasos de orientación, según los resultados de la encuesta de salida, fueron significativamente mayores en el GAI $(8,9 \pm 1,6$ frente a $6,6 \pm 2,3 ; P=0,001)$. Al comparar la diferencia estimada entre el GAI y el GAH, se encontraron mayores reducciones de $\mathrm{HbA1c}$ y del colesterol total en el GAI. Dentro del GAI, se encontraron mejoras considerables en el peso, IMC, HbA1C, colesterol total y C-LDL.

Conclusiones. La capacitación de los MAP mediante una intervención sobre el comportamiento centrada en el paciente para reducir los factores de riesgo de ECV es factible y eficaz para reducir los factores de riesgo de ECV en Ecuador. Los países desarrollados y en desarrollo podrían beneficiarse por igual de tal intervención.

Enfermedades cardiovasculares; capacitación de recursos humanos en salud; diabetes mellitus tipo 2; HDL-colesterol; LDL-colesterol; presión sanguínea; Ecuador.
RESUMO

Impacto da capacitação
de médicos da atenção
primária em orientação
comportamental para
reduzir os fatores de
risco de doenças
cardiovasculares no
Equador

Palavras-chave
Objetivo. Avaliar a viabilidade de implementar um modelo de intervenção do tipo orientação comportamental dirigida ao médico e centrada no paciente para melhorar a capacidade dos profissionais da atenção primária de reduzir os fatores de risco de doenças cardiovasculares nos pacientes.

Métodos. Estudo clínico randomizado conduzido em ambulatórios de atenção primária em Quito, no Equador, de 2014 a 2016. Participaram do estudo 15 médicos da atenção primária e os respectivos pacientes adultos com alto risco de diabetes tipo 2 . Oito participantes fizeram parte de uma intervenção do tipo orientação comportamental dirigida ao médico e centrada no paciente. Os outros sete médicos fizeram parte do grupo de controle que não recebeu a capacitação. A experiência do paciente foi avaliada com uma entrevista de saída. Características antropométricas, medidas de pressão arterial e parâmetros bioquímicos foram avaliados nos pacientes. As mudanças dentro de um mesmo grupo e entre os grupos foram estimadas com o uso do teste do qui-quadrado, ANOVA, teste t pareado e coeficiente com intervenção.

Resultados. Participaram do estudo 197 pacientes ao todo, sendo 113 no grupo de intervenção (GI) e 84 no grupo de atenção de rotina (GR), e completaram o estudo 99 pacientes $(87,6 \%)$ no GI e 63 (75\%) no GR em 2014-2016. O GI recebeu um número significativamente maior $(8.9 \pm 1.6$ vs. $6.6 \pm 2.3 ; P=0.001)$ de orientações, avaliadas na entrevista de saída. Uma comparação da diferença estimada entre o GI e o GR demonstrou maior redução no nível de hemoglobina glicosilada (HbA1c) e colesterol total no GI. Os pacientes do GI tiveram melhora significativa no peso corporal, índice de massa corporal (IMC), colesterol total e LDL.

Conclusões. Capacitar os médicos da atenção primária em uma intervenção comportamental centrada no paciente é uma opção viável e eficaz para reduzir os fatores de risco de doenças cardiovasculares no Equador. Ambos os países desenvolvidos e em desenvolvimento poderiam se beneficiar com esta intervenção.

Doenças cardiovasculares; capacitação de recursos humanos em saúde; diabetes mellitus tipo 2; HDL-colesterol; LDL-colesterol; pressão sanguínea; Equador. 